\title{
AUTOMATION NEEDS DETERMINATION USING AHP APPROACH
}

\author{
Sy-Jye Guo and R. L. Tucker \\ Department of Civil Engineering \\ University of Texas at Austin, TX 78712, U.S.A.
}

\begin{abstract}
There is a consensus among researchers that identification of automation needs is necessary for any further hardware developments. To accomplish this goal, a clear division of automation levels, a comprehensive breakdown of construction activities to task levels, and a method for measuring automation concern are essential. This paper presents an automation spectrum with five automation levels: hand tools, manual-controlled devices, tele-controlled devices, pre-programmed devices, and cognitive robots. Forty-two basic construction tasks are defined to assist in identification and development of automation needs. An Automation Concern Index (ACI) for construction task using the Analytical Hierarchy Process (AHP) is presented to assist in identifying automation needs. The Automation Concern Index serves as a base for automation needs evaluation and can be revised to fit in various construction environments by using the AHP approach.
\end{abstract}

\section{Automation level}

Automation development and implementation should be defined on an appropriate level to become successful based on the current state of technology. It is essential to determine the appropriate level of automation in the task identification phase. Otherwise, a proposed development will become too difficult to implement and turn out to be unfeasible. Tucker [13] has proposed a man-machine line to show the relationship between human conditions and mechanical contributions. On the left end side, manual labor is the only input for the construction task, while on the right end side, a fully roboticized device with cognitive ability is used to complete the job. Both ends represent an extreme status of automation level. Manual labor has been used since the beginning of human civilization and, in many areas of construction work, it is still the major source for construction activity. With the advanced technology in computers, robotics, and new equipment developed in the last decade, roboticization undoubtedily will have many applications in the construction process. Meanwhile, many construction tasks which are labor intensive are still located near the left end of the spectrum. There is potential that these tasks can be significantly improved through some way of automation or partial roboticization.

The automation spectrum is shown in Fig. 1. Typical examples of concrete floor troweling devices are presented to fit in the appropriate intervals. As is still used in many job sites for concrete floor finishing, the manual labor with hand trowel fits in the hand tools interval. Walk-behind and ride-on trowels have been widely used in the U.S. because of the advancement and improvement of both performance and productivity. Both these two power trowels fit in the manual-controlled devices interval. The prototype concrete floor troweling robots developed by Shimizu Corp.[2] and Kajima Corp.[12] in Japan fit in the tele-controlled and pre-programmed intervals respectively. 


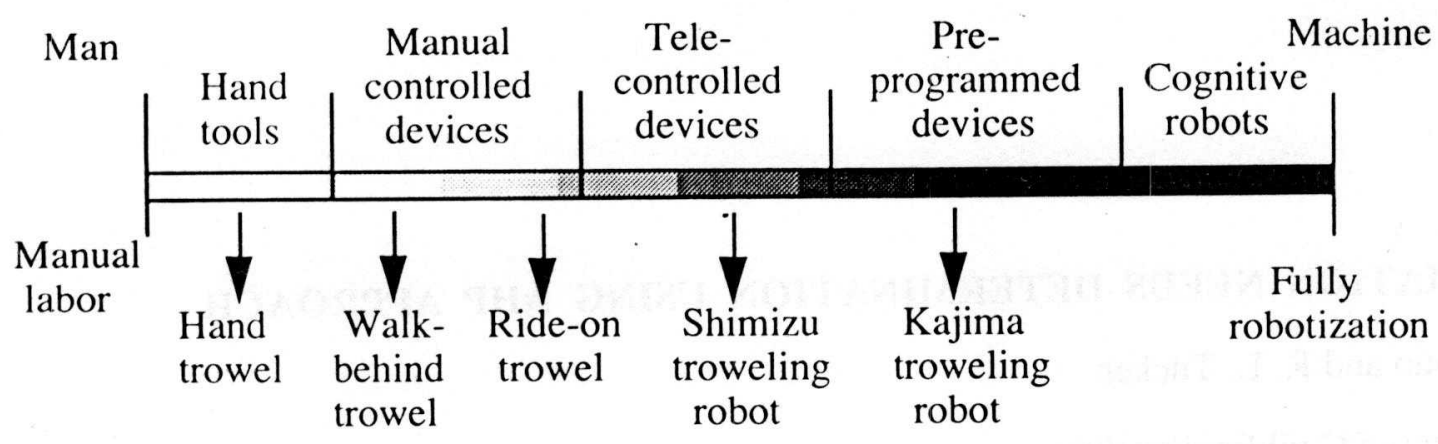

Fig. 1 Automation spectrum

Only a few cases exist in the tele-controlled interval and most of them are prototype devices currently under development. Concrete floor troweling robots developed by Shimizu, Takenaka, and Obayashi Corp. are typical examples in this interval. However, the telecontrolled technology has been widely used in our daily life, such as TV's, VCR's and etc. More and more construction equipment will be upgraded with the tele-controlled technique in the near future. Much more effort and techniques will be needed for developing a preprogrammed device, especially in the control system and sensing ability. Very few prototype devices exist in this category. The Automated Guided Vehicle (AGV) developed by the Caterpillar Corp. is one of the pioneer devices. Kajima's floor troweling robot is another example. The full roboticization with cognitive ability device is the optimal goal of construction automation. However, none of this type of device has yet been developed.

To advance the construction task on the automation spectrum, the appropriate level of automation should first be considered. It may be more feasible to upgrade the level by one interval at a time, e.g., advance hand tools to the manual-controlled level, or upgrade manualcontrolled devices to the tele-controlled level. Only in extreme situations, such as in a radiation polluted area, the deep sea or air space, will fully roboticized devices become the better option. Many difficulties and obstacles will occur if a current hand tool is upgraded directly to the tele-controlled or even pre-programmed level. Not only are difficulties concerned about technology problems, but also the labor resistance results from fear of losing jobs, suspiciousness of performance, or lacking of special skills for new technologies, will inhibit automation progress.

\section{Division of work}

Another significant aspect of construction automation is the division of work to be designed for automation. Because of the complicated nature of construction work, it is important to define the type of task an automated device should perform. For more complex tasks, a device will require more sophistication. The manufacturing industry has utilized many robot applications to replace human workers in production lines and perform single tasks such as painting, welding and bolting. It will be very productive to adapt the experience of the manufacturing industry for developing automation applications in construction tasks.

Some researchers such as Kangari and Halpin [8], Fazio [5], Basford and Askew [1] have identified automation opportunities on a wide range of construction processes. Their subjects range from the task level up to a whole construction division. Tucker and Peterson, et al. [14] have proposed a division definition between areas, activities, and tasks. A typical breakdown example of construction work is shown as below. 
Table $1 \quad$ Area-Artivity-Task example

\begin{tabular}{|l|l|l|}
\hline AREA & ACTIVITY & TASK \\
\hline \hline Concrete & Rebar fabrication & Bend \\
\cline { 3 - 3 } & & Position \\
\cline { 2 - 3 } & & Tie \\
\cline { 2 - 3 } & Concrete placement & Spread Concrete \\
& & Vibrate \\
& & Finish \\
\hline
\end{tabular}

The task level is the simplest and most appropriate level for an automation device. The activity level, which consists of several tasks, becomes more complicated for a single device to complete the work. Not only does the problem of the control system arise, but also the different end effectors, sensors, mobility, and the material supply problems must be addressed. The area level, which is too broad and vague for automation definition, is probably unrealistic during the identification phase.

Some other researchers have tried to identify automation opportunities at the task level to make them more feasible based on the current state of technology. Warsawski and Sangrey [16] presented 10 basic construction "activities" in building construction. Their presentations are actually at the task level. Everett [4] has expanded the list to 18 basic construction tasks which purport to include all the construction activities. Demsetz [3] has utilized a conceptual design process to identify construction tasks for automation. Her study investigates the division of labor between man and machine based on the forces and displacements required to carry out construction work

Based on the experience of the manufacturing industry and the discussion above, the task level is an appropriate level for construction automation. A comprehensive breakdown of construction activities to the task level will be significant in assisting identification of automation opportunities. A list of basic construction tasks has been generated by a panel consisting of professors, researchers, and graduate students in construction Engineering. Forty-two generic construction tasks have been identified and defined as listed in Table 2.

Table 2 Basic Tasks Involved in Construction Activities

\begin{tabular}{|l|l|l|l|}
\hline & Basic Task & Definition & Examples \\
\hline \hline 1 & Arrange & Put a number of objects in a proper order & Arrange rebar \\
\hline 2 & Align & Keep objects in a straight line or orientation & Align steel columns \\
\hline 3 & Bend & Deform the shape of an object & Bend steel rebar \\
\hline 4 & Caulk & Inject sealant between two adjacent objects & Seal concrete joints \\
\hline 5 & Clean & Remove unwanted dirt, material or impurities & Sweep floor \\
\hline 6 & Coat & Apply a layer of liquid on an object's surface & Paint wall \\
\hline 7 & Communicate & Talk or use hand signals to transfer information & Ask or answer \\
\hline 8 & Compact & Condense soil or other material & Compact soil refill \\
\hline 9 & Connect & Join or fasten two objects to each other & Nail, bolt, tie, weld \\
\hline 10 & Cover & Unroll sheet material on an object's surface & Unroll carpet \\
\hline 11 & Cut & Divide one object into two or more pieces & Saw wood, cut tile \\
\hline 12 & Disconnect & Break the connection between two objects & Strip forms, unbolt \\
\hline 13 & Dismantle & Demolish or break down an undesired portion & Dismantle concrete \\
\hline 14 & Drill & Make a hole by rotation & Drill hole \\
\hline 15 & Excavate & Dig out by remove soil or material & Excavate tunnel \\
\hline
\end{tabular}




\begin{tabular}{|l|l|l|l|}
\hline 16 & Fill & Put soil or material in place & Dump soil \\
\hline 17 & Finish & Apply continuous mechanical treatment to surface & Trowel, grind \\
\hline 18 & Hit & Strike hardly to push an object & Hit piles \\
\hline 19 & Hold & Keep an object in a position temporarily & Hold hose, tag line \\
\hline 20 & Identify & Recognize an appropriate member & Identify steel column \\
\hline 21 & Inlay & Set small flat pieces next to each other & Set tiles \\
\hline 22 & Insert & Push an object into another one & Insert form ties \\
\hline 23 & Inspect & Examine and detect flaws or verify correctness & Visually check \\
\hline 24 & Install & Put an object into final position & Install light fixture \\
\hline 25 & Level & Keep material on a horizontal plane & Screed concrete \\
\hline 26 & Lift & Move an object upward for transporting & Lift concrete panel \\
\hline 27 & Lay & Set objects next to or on top of each other & Lay bricks \\
\hline 28 & Measure & Determine or layout correct dimensions & Measure rebar layout \\
\hline 29 & Operate & Control an equipment for work & Operate crane \\
\hline 30 & Position & Move an object to the correct lccation & Position steel beam \\
\hline 31 & Pour & Cast concrete into forms or slabs & Pour concrete slabs \\
\hline 32 & Prepare & Make material ready for future use & Get material \\
\hline 33 & Pull & Draw electrical wire through conduit & Pull cable \\
\hline 34 & Pump & Transport material by air pressure & Pump concrete \\
\hline 35 & Roll & Move an object on wheels along a surface & Roll the flooring \\
\hline 36 & Shape & Modify the shape of an object to fit into position & Trim wood \\
\hline 37 & Spray & Jet liquid or particles without contact with surface & Spray paint \\
\hline 38 & Spread & Apply semi-liquid material to various location & Spread mortar \\
\hline 39 & Tap & Strike or touch an object gently & Tap tiles or bricks \\
\hline 40 & Transport & Move material to designated location & Transport bricks \\
\hline 41 & Vibrate & Shake or tremble to consolidate material & Vibrate concrete \\
\hline 42 & Write & Make note or mark to indicate a specific purpose & Write notes \\
\hline
\end{tabular}

\section{Automation concern factors}

For automation needs concerns, researchers have developed five major factors which motivate automation development. They are safety, productivity, worker utilization, superhuman handling and quality [14]. All these factors are further divided into several subfactors. The hierarchy structure for automation concern with sub-factors is shown in Fig. 2.

Safety concerns arise from the high accident rate of the construction industry. Thus, any task involving a safety concern should be considered for automation. Hazardous to health, physical dangerous, and elevated work are sub-factors defined in this concern. The productivity concern involves aspects such as repetitive, dirty or unpleasant, boring, tedious, and exhaustive work. The manufacturing industry has utilized many robot applications to improve human productivity. Construction tasks with similar natures undoubtedly will gain essential productivity improvement if automation development can be applied. The worker utilization concern deals with the supply and skill level of human labor. As construction jobs are considered to be unsafe, unpleasant, and low-knowledge work, the younger generation is more unwilling to become construction workers. For construction tasks requiring special skills, this situation becomes worse. Special skill requirements and labor intensive are the sub-factors in this category. The super-human handling concern implies tasks which are not appropriate for human workers to handle. For tasks where the requirements exceed the physical capabilities of human labor, some kind of equipment or automation device will be needed to assist in completing the task. Heavy lift, high lift and meticulous tasks are typical 
cases in this category. The quality concern considers both the tolerance level and consistency requirement of a construction task. Much rework commonly occurs on a job site because of poor quality control. Automation development is expect to relieve this problem by achieving a better working quality through the use of machines.

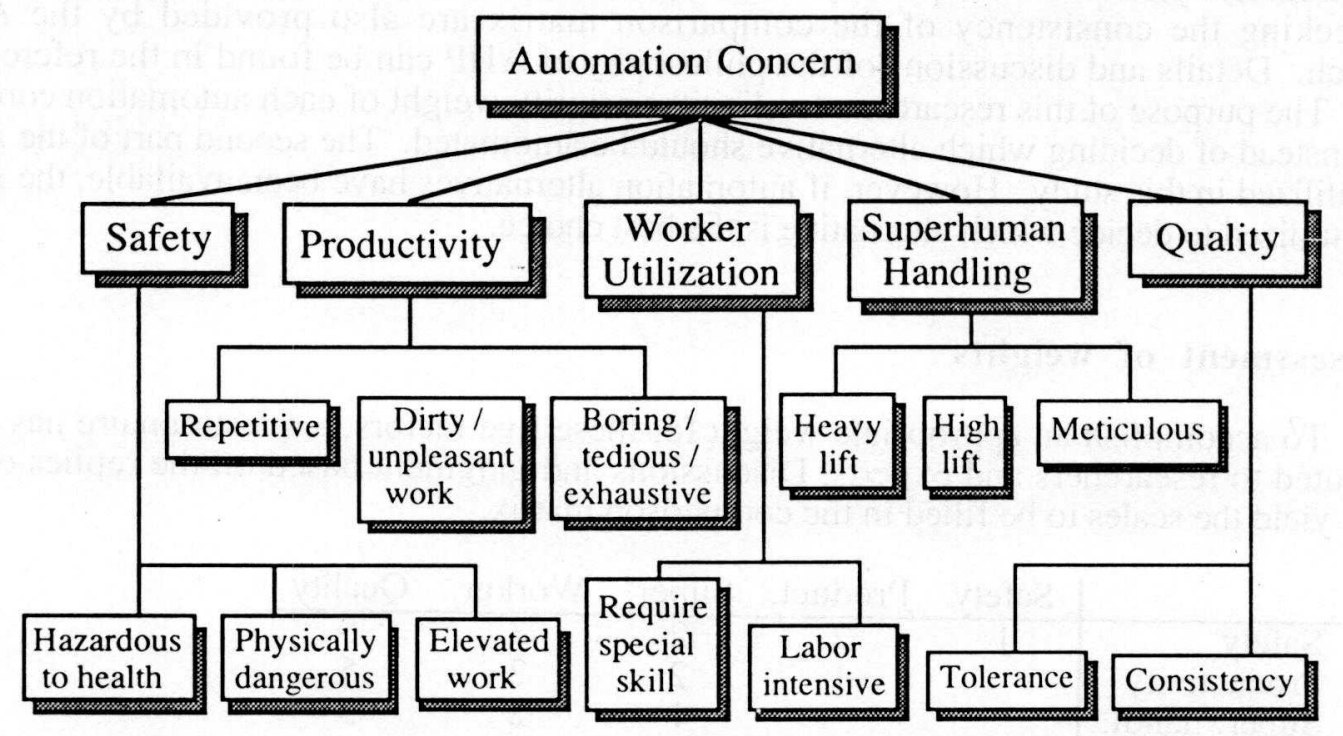

Fig 2 Hierarchy of Automation Concern

\section{Analytic hierarchy process}

An Analytic Hierarchy Process (AHP) was developed by Saaty [10] in the 1980's and utilized in broad application areas, such as decision making, resource allocation, optimization, and etc. [7]. The basic concept of AHP is to develop an hierarchy structure of the factors which contribute to the final goal. By comparing these factors in a matrix format, a priority vector can be derived through mathematical procedures. The coefficients of the priority vector represent an indication of the weight that should be assigned to each factor. Some researchers have also proposed mathematical mechanisms for checking the consistency of these weights. By utilizing AHP, concerns about non-quantitative factors can be effectively presented in a systematic way. Traditionally, researchers intuitively assign a subjective weight to factors which are difficult to quantify. AHP resolves the argument of subjective weights and reaches an objective distribution of priority.

The basic procedure involved in AHP is described as follows:

1. Develop an hierarchical structure of factors and sub-factors contributing to the final goal

2. Rank these factors in order and put them as headings of both rows and columns in the comparison matrix. The comparison matrix will have 1 at all the diagonal cells.

3. Compare these factors relatively with a scale of 1 to 5 and fill in the upper half of the comparison matrix. The scale 1 to 5 represents a ratio comparison of two factors with respect to, $\quad 1:$ two factors contribute equally

2: one factor is slightly favorable than another

3. one factor is moderately favorable than another

4. one factor is strongly favorable than another

5. one factor dominates another

4. Put the reciprocal of each cell to the symmetric cell of the lower half of the matrix.

5. Calculate $\sum$ cell value/column sum to reach a combined weight of each factor.

6. Normalize the combined weight to become a priority vector. 
The coefficient of the priority vector implies the weight of each factor. The second part of the AHP is to aggregate the weight of each alternative based on different factors. A similar matrix is used to compare the alternatives pair-wisely based on only one factor. Combining the priority vector of factors with the priority vector of alternatives based on different factors yields the final priority vector for all the alternatives [10]. Formal procedures for checking the consistency of the comparison matrix are also provided by the AHP approach. Details and discussions of the philosophy of AHP can be found in the references $[7,10]$. The purpose of this research is to elicit the priority weight of each automation concern factor instead of deciding which alternative should be automated. The second part of the AHP is not utilized in this study. However, if automation alternatives have been available, the AHP can be utilized to decide which alternative is the best choice.

\section{Assessment of weights}

To accomplish an appropriate weight for these five factors, a questionnaire has been distributed to researchers and experts. Discussions and judgment based on the replies of the survey yield the scales to be filled in the comparison matrix.

\begin{tabular}{l|ccccc} 
& Safety & Product. & Super. & Worker. & Quality \\
\hline Safety & 1 & 2 & 2 & 3 & 5 \\
Productivity & & 1 & 2 & 2 & 5 \\
Super. handl. & & & 1 & 2 & 5 \\
Worker util. & & & & 1 & 4 \\
Quality & & & & & 1
\end{tabular}

Once the comparison scales are determined, the reciprocal of each cell is put into the lower half of the matrix, and the column sums are calculated. Then, the row sum is calculated

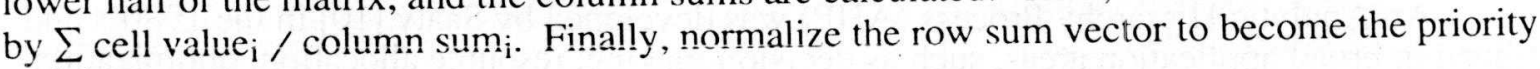
weight vector.

\begin{tabular}{l|ccccccc} 
& Safety & Product. & Super. Worker. & Quality & Row sum & Weight \\
\hline Safety & 1 & 2 & 2 & 3 & 5 & 1.84 & 0.37 \\
Productivity & $1 / 2$ & 1 & 2 & 2 & 5 & 1.28 & 0.26 \\
Super. handl & $1 / 2$ & $1 / 2$ & 1 & 2 & 5 & 0.98 & 0.20 \\
Worker util. & $1 / 3$ & $1 / 2$ & $1 / 2$ & 1 & 4 & 0.66 & 0.13 \\
Quality & $1 / 5$ & $1 / 5$ & $1 / 5$ & $1 / 4$ & 1 & 0.24 & 0.05 \\
\hline Column sum & 2.53 & 4.20 & 5.70 & 8.25 & 20.00 & 5.00 & 1.00
\end{tabular}

Following the mathematical procedures listed above, a preliminary weight of each factor has been reached as follows :

Automation Concerns Index (ACI)

$=0.37 *$ Safety $+0.26 *$ Productivity $+0.20 *$ Super. handl.

$+0.13 *$ Worker util. $+0.05 *$ Quality

\section{Automation Concern Index}

To reach a final index, all the sub-factors for each concern are assigned a value of 0 or 1 and summed to be the input for each specific concern. The value 1 indicates that the task is concerned with this sub-factor, and the value 0 means the task is not associated with this subfactor. For example, vibrating concrete is concerned with the following sub-factors: 
repetitive, dirty and unpleasant, boring and tedious, labor intensive, and consistency required. No safety sub-factors are related but three productivity sub-factors are associated. Thus, the input values of safety and productivity for vibrating concrete are 0 and 3 . Similarly, the super-human handling, worker utilization, and quality concern are assigned as 0,1 , and 1 respectively. The Automation Concern Index for vibrating concrete can be calculated as

$$
\mathrm{ACI}=0.37 * 0+0.26 * 3+0.20 * 0+0.13 * 1+0.05 * 1=0.96
$$

This binary decision is quite rational and easy to follow. However, this approach reveals the relative concern of different tasks for each sub-factor. To implement this approach, an interview with foremen on a viaduct girder construction job site was held to decide if each sub-factor was related to different tasks. Judging from the responses of the foremen, 16 task examples were given automation indices in Table 3 according to the equation above.

The ACI derived from the equation ranges from 0 to a possible maximum value of 2.85 if all sub-factors apply. For tasks listed in the Table 3 , the sample mean $(\mu)$ is 1.24 and standard deviation $(\sigma)$ is 0.29 . Because few construction task will involve all these five concerns at the same time, most tasks will have an index between 1 to 2 . Hence, index greater than 1.43, half of the maximum value, is recommended for automation consideration. Weld rebar, position parapet segment, plaster concrete surface, grind concrete surface, and fireproof steel frame are tasks qualified for this consideration.

The Automation Concern index (ACI) is designed to quantify the intangible motivation for automation development. It does not consider the cost impact in the concern hierarchy, neither are the technology factors considered. The cost impact is a quantifiable prospect and should be compared with the concern index while identifying automation needs. To identify potential candidates for automation development, the technical consideration should then also be addressed and investigated. Definition of an appropriate level in respect to the automation spectrum and clear division of construction tasks will definitely be helpful to further hardware development.

Table $3 \quad$ Automation concern indices for tasks

\begin{tabular}{|l|c|c|c|c|c|c|}
\hline Task & Safety & Product. & Super. & Worker. & Quality & ACI \\
\hline \hline Vibrate concrete & 0 & 3 & 0 & 1 & 1 & 0.96 \\
\hline Spread concrete & 0 & 3 & 0 & 1 & 0 & 0.91 \\
\hline Level concrete & 0 & 3 & 0 & 2 & 1 & 1.09 \\
\hline Weld rebar & 2 & 2 & 0 & 2 & 1 & 1.57 \\
\hline Arrange rebar & 1 & 2 & 1 & 1 & 1 & 1.27 \\
\hline Position veneer & 1 & 2 & 2 & 1 & 0 & 1.42 \\
\hline Tap compacting & 0 & 2 & 0 & 1 & 1 & 0.70 \\
\hline Chip pile head & 1 & 3 & 0 & 1 & 0 & 1.28 \\
\hline Position parapet & 2 & 1 & 2 & 2 & 0 & 1.66 \\
\hline Bolt parapet & 2 & 1 & 0 & 1 & 1 & 1.18 \\
\hline Clean form & 1 & 2 & 0 & 1 & 0 & 1.02 \\
\hline Nail form & 1 & 1 & 0 & 2 & 1 & 0.94 \\
\hline Plaster concrete & 1 & 3 & 0 & 2 & 1 & 1.46 \\
\hline Grind concrete & 2 & 3 & 0 & 1 & 1 & 1.70 \\
\hline Bush hammering & 1 & 2 & 0 & 2 & 1 & 1.20 \\
\hline Fireproof steel & 2 & 2 & 0 & 1 & 1 & 1.44 \\
\hline
\end{tabular}




\section{Conclusions}

Identification of automation needs and opportunities are essential for any hardware development. To identify a feasible automation candidate, an appropriate automation level should be defined, the working content should be broken down to the task levels, and the motivation for automation concern should be evaluated. An automation spectrum defined with five levels is presented in this study. Advancement of the automation level of current construction practice by one level is recommended. Forty-two basic construction tasks have been defined to assist in identification of automation needs. Finally, the Automation Concern Index (ACI) using the Analytic Hierarchy Process is presented. The AHP is an excellent approach for evaluating intangible concerns. The Automation Concern Index serve as a base for automation needs evaluation and can be utilized and revised to fit any construction environment by using the AHP approach. Combining the ACI with further cost impact concerns allows potential automation candidates to be identified [6].

\section{References}

1. Bashford, S. F., Askew, W.H. et al.,"Initial Task Selection for Detailed Robotic Evaluation", The 9th ISARC; 1992, Japan, pp 141-150.

2. Cranmer, Lee R. and Tucker, R. L.; Operational Test and Evaluation of Automated Construction Device, Construction Industry Institute, SD-59, 1990.

3. Demsetz, L.; "Task Identification for Construction Automation"; The 6th ISARC; 1989, San Francisco, pp 95-102.

4. Everett, J.; "Back to Basics in Construction Automation"; The 7th ISARC; 1990, London, pp 583-590.

5. Fazio, P., Moselhi, O., and Hason, S.; "Automation Index for Evaluation of Robotics Implementation in Construction"; The 6th ISARC; 1989, San Francisco, pp 317-324.

6 Guo, Sy-Jye; "Automation Needs Identification for the Taipei Rapid Transit System Project ", Dissertation, University of Texas at Austin, May 1993.

7. Harker, P.; "The Art and Science of Decision Making: The Analytical Hierarchy Process"; The Analytic Hierarchy Process Applications and Studies, Springer-Verlag Berlin Heidelberg, New York,1989, pp 3-58.

8. Kangari, R. and Halpin, D. W.; "Automation and Robotics in Construction: A Feasibility Study"; The 5th ISARC; 1988, Tokyo, pp 161-167.

9. Kangari, R. and Halpin, D. W.; "Potential Robotics Utilization in Construction"; Journal of Construction Engineering and Management, Vol. 115, No. 1, March, 1989, ASCE, pp 126-143.

10. Saaty, T. L.; Decision Making for Leaders: The Analytical Hierarchy Process for Decisions in a Complex World, Lifetime Learning Publications, California, 1982

11. Skibniewski, M. J.; Robotics in Civil Engineering, New York, Van Nostrand Reinhold Publisher, 1988.

12. Tanaka, N. et al, Kajima Corporation; "The Development of the 'Mark II' Mobile Robot for Concrete Slab Finishing", CAD and Robotics in Architecture and Construction, Proceedings of the Joint International Conference at Marseilles, France, 1986,pp 249-257.

13. Tucker, Richard L.; "High Payoff Areas for Automation Applications"; The 5th ISARC; 1988, Tokyo, pp 9-16.

14. Tucker, Richard L., et al; A Methodology for Identifying Automation Opportunities in Industrial Construction. Construction Industry Institute, SD-56, 1990.

15. Warszawski, A.; Industrialization and Robotics in Building--A Managerial Approach, New York, Harper \& Row Publishers, 1990.

16. Warszawski, A. and Sangrey, D. A.; "Robotics in Building Construction"; Journal of Construction Engineering and Management, Vol. 111, No. 3, March, 1985, ASCE, pp 260-280. 